\title{
The use of geoinformation technologies for renewable energy and regional aspects of developing renewable energy in Russia
}

\author{
Y.Y. Rafikova ${ }^{1, a}$, S.V. Kiseleva ${ }^{1}$, L.V.Nefedova ${ }^{1}$ and S.E. Frid ${ }^{2}$ \\ ${ }^{1}$ Laboratory of Renewable Energy Sources, Faculty of Geography, Lomonosov Moscow State \\ University, 119991, Leninskie gory 1-19, Moscow, Russia \\ ${ }^{2}$ Laboratory of Renewable Energy Sources and Energy Saving, Joint Institute For High Temperatures \\ of the Russian Academy of Sciences, 125412, Izhorskaya st. 13-2, Moscow, Russia
}

\begin{abstract}
The work presents the results of development of the geoinformation system "Renewable Energy Sources of Russia". Regional maps of installations and resources are presented. The problem of determination of small hydropower potential connected with the shortage of hydrological data is stated. Assessment of efficiency of techno-economic analysis of simulation-based autonomous solar lighting systems is described. Overview of regional experience, policies and targets is included.
\end{abstract}

In many countries of the world renewable energy (RE) has already become a dynamically developing branch of energy generation, mechanical engineering, fundamental and applied sciences, equipment and technology. Thus the main purpose of RE development is finally ensuring access for consumers to energy, diversification of energy sources, consolidation of energy security in regions and states. The consumer, both at the level of government and at the level of the end-user, first of all needs extensive and diverse information about: technical means, renewable energy resources, economic aspects (profitability and equipment payback period), experience of development and use of power supply systems on renewable energy sources and installed objects working on RE.

Due to this fact the process of developing and providing the consumer with various information resources was started in many countries: at first it was printed products, later it became digital, including access to the Internet. Owing to great value of the geographical aspect during work with data files in the field of RE, geoinformation (GIS) technologies are actively used. These resources are provided both on commercial basis, and in open access.

The assessment of renewable energy resources in Russia, were certainly carried out long before the emergence of modern mapping means and data analysis. Nevertheless now there is a question not only in general estimates, but also more exact local data on the renewable energy sources corresponding to inquiries of experts in the field of power plant design, development of data acquisition regulations and their accuracy. The advantage of using GIS-technologies and the need for cooperation of experts from such fields as physics, technics and geography is obvious.

\footnotetext{
${ }^{a}$ Corresponding author: ju.rafikova@gmail.com
}

This is an Open Access article distributed under the terms of the Creative Commons Attribution License 4.0, which permits unrestricted use, distribution, and reproduction in any medium, provided the original work is properly cited. 


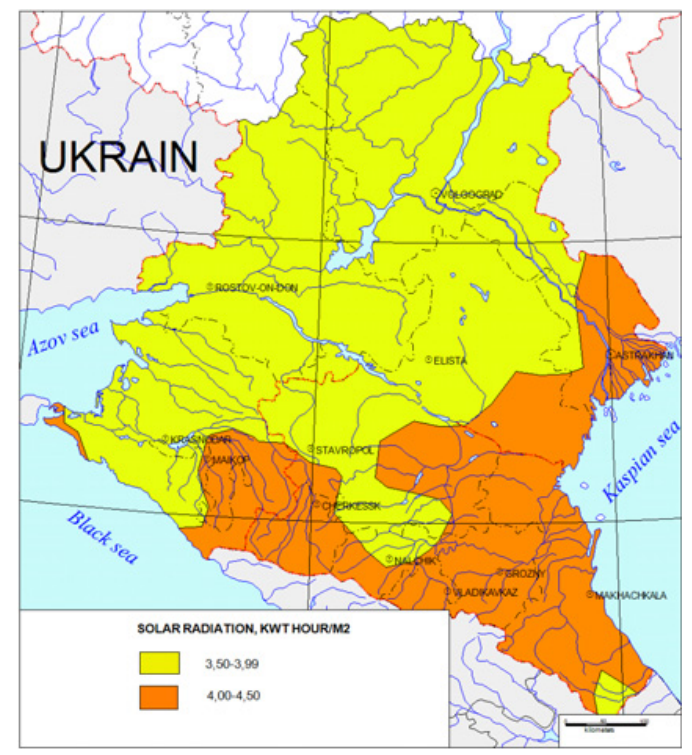

Figure 1. Distribution of average solar radiation for the South of Russia.

The project "Geoinformation system "Renewable energy sources of Russia" (http://www.gis-vie.ru/) which was carried out by the Faculty of Geography, Lomonosov Moscow State University and the Joint Institute of High Temperatures of the Russian Academy of Sciences within the Scientific and educational center "Renewable energy sources" became the basis for formatting and working out approaches and methods of assessing different types of renewable energy sources, and also aggregating all actual information in the field of renewable energy of Russia.

The following data are currently presented on the site of the project:

1. Maps of solar, wind and bioenergy characteristics distribution, and also maps of some technical characteristics (for example, a probability of hot water supply loading by means of solar waterheating installations of set-capacity) (Fig. 1, Fig. 2).

2. Information on objects and projects of renewable power in Russia with their short description (Fig. 3).

3. Tables with characteristics of renewable energy sources (for bio- and geothermal energy sources).

4. Procedures of some renewable energy characteristics calculations.

5. The atlas of solar energy resources for the Russian Federation territory.

The scheme of the GIS, background and the data were described in [1]. In this work new results on hydropower block development are considered.

In the research of the small hydropower (SHP) block of GIS "RES in Russia" the structure of the database (DB) was formed from the analysis of information resources, hydropower needs assessments and calculations. It was justified that the database GIS Resources of SHP should contain maps, attribute, text and graphic information, archives of space images. The cartographic component of the database must contain vector information of different scales about: the geographic and hydrological layers, the layers of hydropower plants and other waterworks and the environment layer group, including information on protected areas, etc. The database of operated Small Hydropower Plants (SHPP), containing information on the location, the date of construction, the operator, the capacity of SHPP and annual Energy output was formed. 
$3^{\text {rd }}$ European Energy Conference

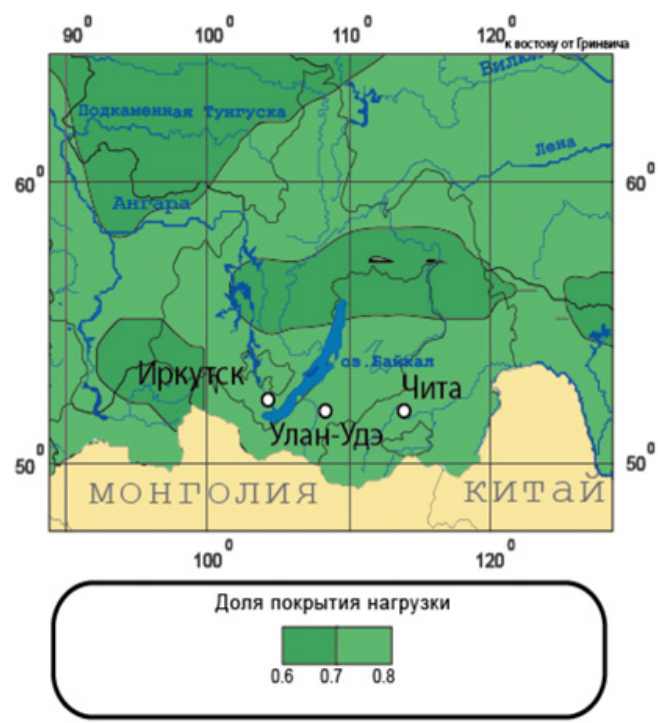

Figure 2. Probability of hot water supply loading by means of solar water-heating installations of set-capacity $\left(37^{\circ} \mathrm{C}\right.$, summer, $\left.\mathrm{S}=2 \mathrm{M}^{2}\right)$.

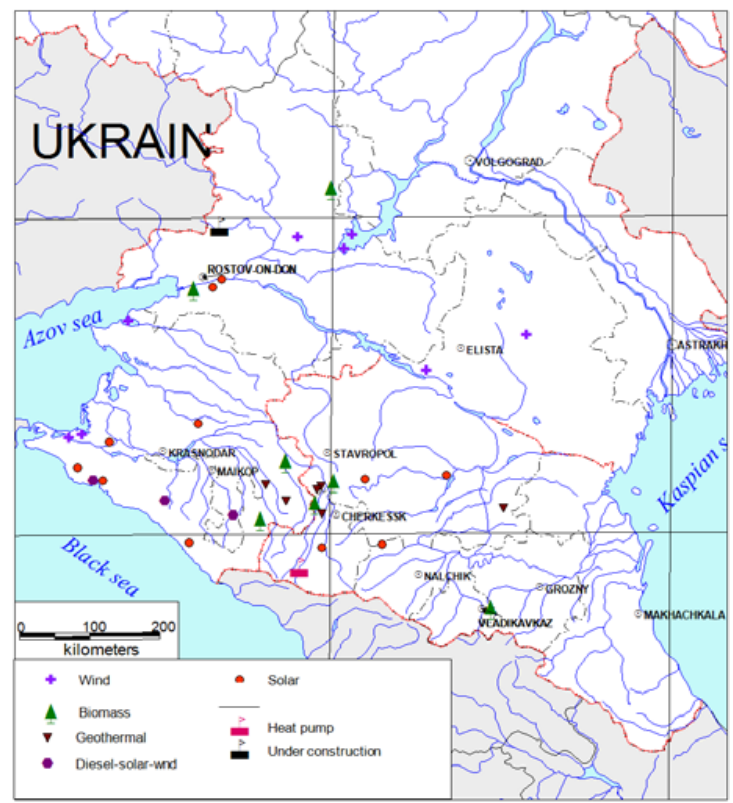

Figure 3. Installations and projects on renewables at the South of Russia.

A specific feature of small rivers is the exceptional dependence of water resources on local landscape and geographic features of the water catchment area. For this reason, the constrained water resources of small rivers have greater variability in time and space. In forming of the hydrological layers of the DB significant problems arose related to shortage of hydrological data: absence in Russia of hydrological 
data in public domain, a small amount of hydrological observation stations on small rivers, the weak development of hydrological models for the flow of small rivers.

To solve this problem estimations and calculations of the total hydropower potential at three levels were suggested, depending on the purpose of the research: macro-, meso-and micro-levels; it was also suggested to carry out calculations of the flow of characteristics using the methods of the lack of observational data at the macro - and meso-levels according to the multi-annual mean values of the runoff intensity, figures of variation and asymmetry. In this case it is necessary to create GIS layers containing a hydrological zoning map (for estimates of runoff distribution throughout the year), a map of runoff intensity, regional factors reducing runoff intensity values depending on the catchment area of small rivers, forestry and swampiness. For estimates of the riverbed slope aimed at creating GIS any scale models are appropriate to apply the digital elevation models (DEM). To calculate the parameters of the required water flow probability, regional runoff probability curves are essential, whose form is determined by the values of the coefficients of variation and asymmetry. It is recommended also to evaluate runoff distribution in characteristics of high-water, average-water and low-water years. More exact estimates of the values of the flow required for hydropower specific calculations of a small river, a choice of perspective location of SHPP (micro level) can be obtained by detailed hydrological calculations and, if appropriate, observations and research areas in accordance with accepted engineering hydrology methods.

Also there are some results in efficiency of the techno-economic analysis of simulation-based autonomous solar lighting systems.

The principal differences between renewable energy power plants and traditional plants on fossil fuel are determined by low flows of energy density and their volatility. As a result of the high capital costs required to build such facilities, as well as storage of generated energy. High initial cost of the units requires optimization of their composition and configuration. In this case, virtually the only means of optimization of the plant becomes simulation of its work in specific climatic conditions and at a particular load.

Elements of such power plants are complex objects, which occur in a variety of interrelated physical processes. Oversimplification of the functional description of the individual devices, fails to adequately optimize the composition of the power plant, to define rational modes of individual devices and the installation as a whole. We used the convenient and currently the de facto standard for simulation of power plants using renewable energy sources of dynamic systems simulation environment TRNSYS, developed at the University of Wisconsin (USA). Environment allows to simulate the behavior of systems described by ordinary differential equations, and is a collection of Fortran modules. The configuration of the simulated system is user-defined in a special file describing relationships between system elements. This file in the latest versions of TRNSYS generated by a special program with a user friendly graphical interface.

As the simulation objects, we chose the most widely used systems using solar energy - solar water heaters $(\mathrm{SWH})$. Traditional indicator of energy efficiency of solar energy for water heating is the percentage cover of hot water supply load for consumers through solar energy - solar fraction $f$ :

$$
f=\frac{Q_{\text {solar }}}{Q_{\text {total }}}=\frac{Q_{\text {solar }}}{Q_{\text {solar }}+Q_{P H}}
$$

where $Q_{\text {solar }}$ - energy from solar radiation, which went for water heating, $Q_{\text {total }}$ - the total energy used to heat the water to the required temperature of the consumer. This energy is equal to the sum $Q_{\text {solar }}$ and energy, let down from the backup heater, $Q_{P H}$. Solar fraction $f$ ranges from 0 to 1.

Another measure of the effectiveness of SWH along with solar fraction provides information on the plant operation and is more understandable and clear to potential users, which are not always versed in the intricacies of the energy balance. This indicator defines the number of days $N_{t>t^{*}}$ for a certain period of time (month, season, half year), in which the water in the storage tank of the SWH is heated 


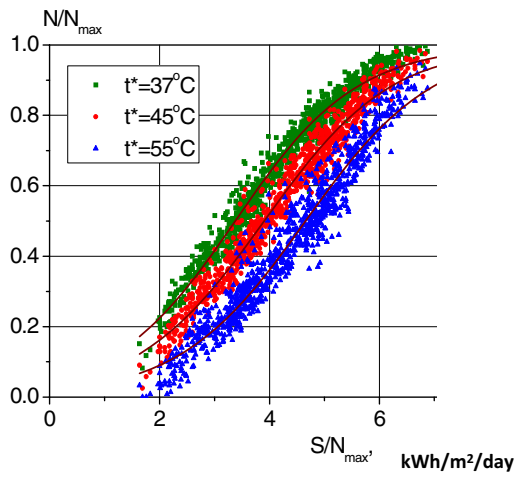

Figure 4. The simulation results of typical SWH throughout the year $\left(N_{\max }=365\right)$, the collector area of $2 \mathrm{~m}^{2}$.

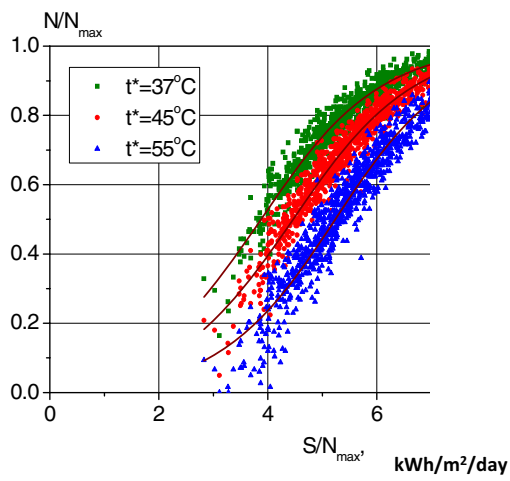

Figure 5. The simulation results of typical SWH throughout the warm half-year $\left(N_{\max }=183\right)$, the collector area of $2 \mathrm{~m}^{2}$.

by solar energy to a temperature not lower than the control $\left(t^{*}\right)$. If the period under review contains $N_{\max }$ calendar days, the corresponding export share is as follows:

$$
n_{t>t^{*}}=\frac{N_{t>t^{*}}}{N_{\max }}
$$

Examples of our simulations in a generalized form are shown on Figs. 4-6. Figures show the dependence $n_{t>t^{*}}$ of the averaged insolation incident on a horizontal surface. The calculations were performed for different periods of the year and for typical SWH with an area of $2 \mathrm{~m}^{2}$ solar collector.

The maps presented on the site [3] show the calculated efficiency of a typical solar water installation with a collector area of $2 \mathrm{~m}^{2}$. The maps show the spatial distribution of the above factors: the specific number of days $n$ when water heats to a temperature of not less than $37^{\circ} \mathrm{C}$, and solar fraction $f$ for the warm half-year (april - september) and summer months (june - august) (Fig. 2).

At summer in most parts of southern Russia and much of Siberia solar fraction $f$ is $0.9 \ldots 1$. Rest of the country is characterized by $f$ about $0.8 \ldots 0.9$ and only on relatively small areas north-west of the country and parts of the Russian Far East $f$ is $0.6 \ldots 0.8$.

Getting the water with a temperature below $37^{\circ} \mathrm{C}$ for $80 \ldots 90 \%$ of summer days is possible in parts of the North Caucasus, Buryatia and Tuva, on the part of the territory of Yakutia. For most of Russians getting hot water daily in the summer time with a probability greater than $60 \%$ is still very high. Only 


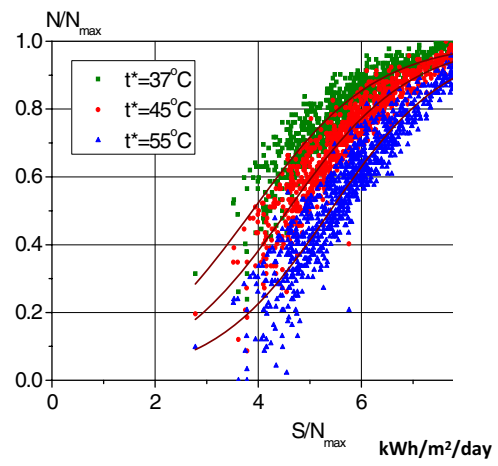

Figure 6. The simulation results of typical SWH throughout the summer $\left(N_{\max }=92\right)$, the collector area of $2 \mathrm{~m}^{2}$.

on the edge of the western, north-western and eastern areas of the specific value of the number of days $n_{t>37^{\circ}}$ in the summer time is below $50 \%$.

Indicators considered for the warm half of the year compared with the summer period decreases slightly, but remain relatively high. This suggests a high efficiency solar water heating systems in most parts of Russia.

At the current stage of the project our aims are:

- mapping constraints relevant criteria to project on renewable at regional level

- develop an approach meant to identify the most promising sites for installations on renewables

- mapping socio-economical aspects of development of renewable energy in Russia on the regional level.

In Russia the systems of centralized power supply covers only 1/3 of the Russian Federation territories, and for $70 \%$ of the territory with the population about 20 million people power supply of consumers is carried out mainly by means of independent power installations working on expensive imported liquid fuel or with use of local resources (coal, wood fuel, peat, etc.) [2].

Now, after the long period of unreasonable expectations of initiatives from the ministries and departments of Russia on development of renewable power, we can observe an interest for renewable energy systems at the regional level. On May 23, 2013 the Russian Government signed a set of measures to support renewable energy sources through the mechanisms of the wholesale electricity market. Due to the big territory of the country we consider very different needs and potentials in the regions of Russia. Some regions have target programs for developing renewable energy, orders and instructions of regional authorities. Such regions are the Krasnodar, Stavropol and Primorsky Krai, the Arkhangelsk oblast, the Republics of Karelia, Bashkiria, Tyva and Buryatiya. Realization of different scaled projects at these regions and republics is connected with a number of factors, including regional specifics - from natural energy resources to social and demographic and power balances. To consider, estimate and analyze all these factors we need to create an extensive arrays of information, and also use analyzing tools which would allow to collect, operatively modernize, transform and display these data files, to receive on their basis reasonable estimates and to do calculations.

We expect, that for Russia it is most relevant to develop renewable power in the territories of independent power supply. The renewable energy sources potential estimations have to be based on analyzing of multi-scaled dynamic cartographic materials and modelling results.

Developed Renewable energy sources GIS of Russia can be in demand by individuals, the municipal and federal state organizations of power and ecological profile, design organizations, research and educational institutions. 
$3^{\text {rd }}$ European Energy Conference

This work was financially supported by the Russian Foundation for Basic Research, grant No. 13-08-01186-a.

\section{References}

[1] Estimating Renewable Energy Resources of Russia: Goals and Perspectives Kiseleva S., Rafikova J., Shakun V. EPJ Web of Conferences, 33, 01003-p.1-01003-p.6, (2012)

[2] V.E.Fortov, O.S.Popel, Power in the modern world. (Publishing house "Intellekt", 2011)

[3] www.gis-vie.ru 